\title{
The Mechanical Impact of the Tibetan Plateau on the Seasonal Evolution of the South Asian Monsoon
}

\author{
HYO-SEOK PARK \\ California Institute of Technology, Pasadena, California \\ JOHN C. H. CHIANG \\ Department of Geography, and Berkeley Atmospheric Science Center, University of California, Berkeley, Berkeley, California \\ SIMONA BORDONI \\ California Institute of Technology, Pasadena, California
}

(Manuscript received 20 May 2011, in final form 3 October 2011)

\begin{abstract}
The impact of the Tibetan Plateau on the South Asian monsoon is examined using a hierarchy of atmospheric general circulation models. During the premonsoon season and monsoon onset (April-June), when westerly winds over the Southern Tibetan Plateau are still strong, the Tibetan Plateau triggers early monsoon rainfall downstream, particularly over the Bay of Bengal and South China. The downstream moist convection is accompanied by strong monsoonal low-level winds. In experiments where the Tibetan Plateau is removed, monsoon onset occurs about a month later, but the monsoon circulation becomes progressively stronger and reaches comparable strength during the mature phase. During the mature and decaying phase of monsoon (July-September), when westerly winds over the Southern Tibetan Plateau almost disappear, monsoon circulation strength is not much affected by the presence of the Tibetan Plateau.

A dry dynamical core with east-west-oriented narrow mountains in the subtropics consistently simulates downstream convergence with background zonal westerlies over the mountain. In a moist atmosphere, the mechanically driven downstream convergence is expected to be associated with significant moisture convergence. The authors speculate that the mechanically driven downstream convergence in the presence of the Tibetan Plateau is responsible for zonally asymmetric monsoon onset, particularly over the Bay of Bengal and South China.
\end{abstract}

\section{Introduction}

Atmospheric general circulations models (AGCMs) consistently simulate a stronger South Asian summer monsoon in the presence of the Tibetan Plateau (Hahn and Manabe 1975; Kutzbach et al. 1989; Prell and Kutzbach 1992; Yasunari et al. 2006; Boos and Kuang 2010, hereafter BK10) leading many to investigate the role that elevated topography plays in monsoonal circulations. A view, which has been prevailing since the classical studies by Yeh et al. (1957) and Flohn (1957), interprets the Tibetan Plateau as an elevated heat source

Corresponding author address: Hyo-Seok Park, MC 100-23, California Institute of Technology, Pasadena, CA 91125-2300.

E-mail: hyo@caltech.edu driving the Asian monsoon, with sensible and latent heat fluxes dominating over the eastern and western Plateau, respectively (Luo and Yanai 1984; Webster et al. 1998; Wu and Zhang 1998; Yanai and Wu 2006). An alternative hypothesis has, however, been emerging in recent years, by which the Tibetan Plateau prevents dry and cold extratropical air from "ventilating" the moist and warm tropics and subtropics (Chou et al. 2001; Prive and Plumb 2007). Indeed, in a recent modeling study, BK10 showed that the main circulation and thermodynamical features of the South Asian monsoon were largely unaffected in GCM experiments in which the Tibet was removed but a narrow Himalaya was retained. By this view, elevated topography would alter the thermodynamics of monsoonal circulations by acting as a "thermal insulator" rather than as a direct heat source. 
This new view of the Tibetan Plateau as an obstacle rather than a heat source for the monsoonal flow calls for a reevaluation of its possible mechanical effects on the summer monsoon, which in the literature have received relatively little attention. Westerly winds over the Tibetan Plateau are substantial until the early monsoon season, so many orographically induced northern winter stationary wave theories are still applicable (Held et al. 2002). Here, we hypothesize that mechanically induced convergence/ divergence can substantially affect the northern summer stationary waves by distributing the diabatic heating field. In terms of mass conservation, longitudinally sloping topography forces vertical motions $[w=U(d h / d x)$; Held et al. (2002) and Smith (1980)] in the presence of westerly winds. In the context of a linear framework, this forced vertical motion could be balanced by anticylonic and cyclonic motions upstream and downstream, respectively (Cook and Held 1992). However, linear theories are always challenged by vertical stretching or shrinking. For smaller-scale motions, the forced vertical motion may well affect the horizontal convergence-divergence field over the mountain (Smith 1980).

Previous AGCM studies suggested that the Tibetan Plateau could produce downstream convergence in boreal spring, though the underlying mechanisms were not fully explored. Wu et al. (2007) demonstrated that the Tibetan Plateau altered the prevailing westerly flow in spring, mechanically inducing convergence downstream of the plateau, and substantially increasing rainfall over South China during March and April. The upstream divergence/downstream convergence pattern was argued to be caused by deflection and splitting of the westerly jet in a northern and southern branch. The meridional range of the Tibetan Plateau is an essential surface boundary condition for the argument of Wu et al. (2007), but we will later show that east-west-oriented, latitudinally narrow mountains can produce downstream convergence.

$\mathrm{Wu}$ et al. (2007) focused on the influence of the downstream convergence on regional-scale patterns, particularly over South China, during one specific season-boreal spring. In this study, we examine the downstream convergence signal throughout the spring and the summer monsoon seasons and further investigate how the downstream convergence affects the larger-scale Asian monsoon circulation. Methodologically, we vary the height and area of mountains in a comprehensive GCM. To more clearly explore the dynamics at play, we also study the circulation response of a dry dynamical core to a Tibetanlike plateau. We focus on two different seasons, before [April-June (AMJ)] and after [July-September (JAS)] the mature phase of the monsoon. Before monsoon onset, in May, westerly wind speeds over the Southern Tibetan Plateau are significant-around $8-12 \mathrm{~m} \mathrm{~s}^{-1}$ in the midtroposphere (500-600 hPa; Figs. 1a,d). In the presence of upper-level westerlies, Rossby waves generated by the Tibetan Plateau can propagate upstream and induce zonally asymmetric circulation patterns. Thus, it is easier to define the mechanical effect of the Tibetan Plateau before the monsoon onset. In June, during and after monsoon onset, westerly winds shift northward and easterlies develop in the equatorial upper troposphere (Figs. 1b,e). During the mature phase of monsoon, in July and August, westerly winds almost disappear over the Southern Tibetan Plateau, while equatorial easterlies get stronger and wider (Figs. 1c,f). Thus, the mechanically driven downstream convergence is expected to decrease during the course of monsoon development.

\section{Model and data}

To understand the role of the Tibetan Plateau on the onset of the South Asian summer monsoon, a set of AGCM experiments have been conducted. We use the Geophysical Fluid Dynamics Laboratory (GFDL) Atmosphere Model, version 2.1 (AM2.1) (GFDL Global Atmospheric Model Development Team 2004). This version of AM2.1 uses a finite-volume dynamical core (Lin 2004) at $2.5^{\circ} \times 2.0^{\circ}$ horizontal resolutions (M45) with 24 vertical levels (L24). Climatologically fixed SSTs are specified as a boundary condition. The SSTs are from the 50 years monthly mean Reynolds reconstructed historical SST analysis, spanning from 1950 to 2000 (Smith et al. 1996). GFDL Climate Model, version 2.1 (CM2.1), a fully-coupled atmosphere-ocean GCM, sharing the same atmospheric model with AM2.1, is known as among the 6 models out of 18 Intergovernmental Panel on Climate Change (IPCC) models that more realistically simulate the South Asian summer monsoon (Annamalai et al. 2007). The South Asian summer monsoon rainfall pattern simulated by AM2.1 looks qualitatively consistent with CM2.1, giving us confidence on the model performance.

To verify the robustness of our interpretations, we also performed experiments with AM2.1 coupled to a motionless slab ocean of uniform depth. A climatological monthly $Q$-flux correction was applied at slab ocean grid points to ensure that the simulated SST seasonal climatology closely matches the observed climatological mean SSTs in the presence of the Tibetan Plateau. Using an AGCM coupled to a slab ocean as opposed to using fixed SST offers a distinct advantage that surface energy balance is maintained over the oceans. On the other hand, the climate-mean SSTs can change in the absence of the Tibetan Plateau, which would complicate interpretations. We tested two different mixed layer depths, one with a 35-m mixed layer depth, a value that is chosen 
(a)

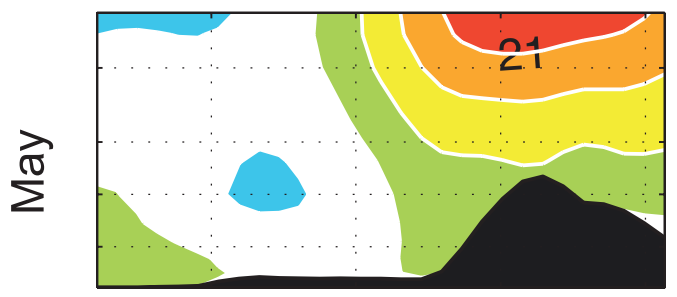

(b)

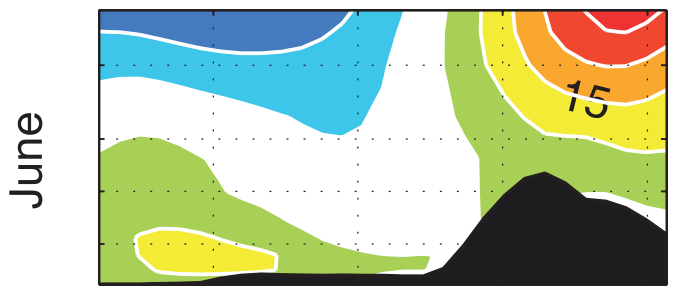

(c)

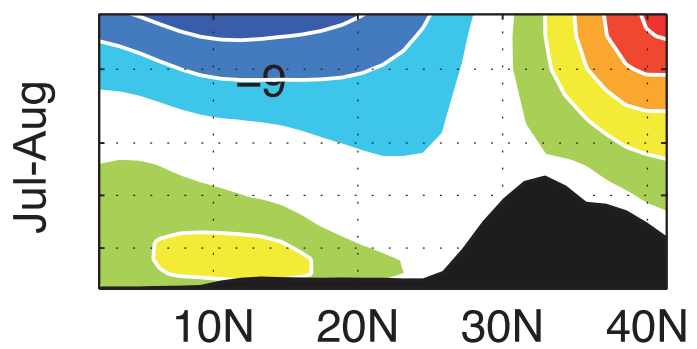

AM2.1

(d)

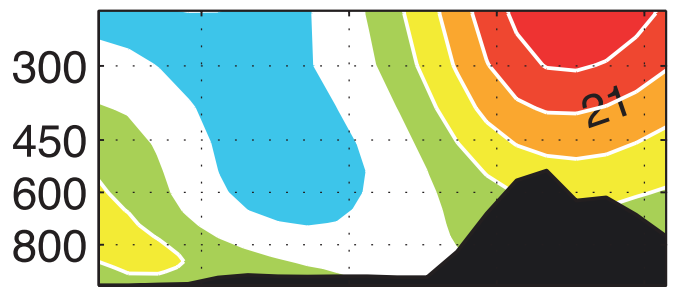

(e)

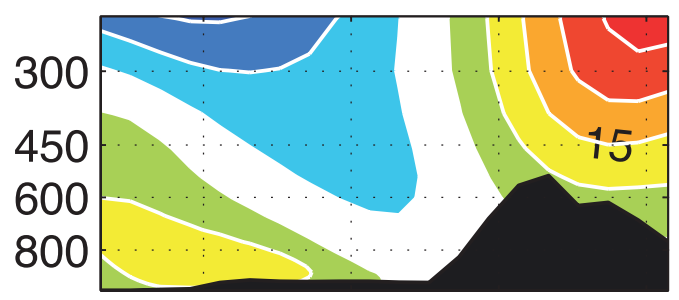

(f)

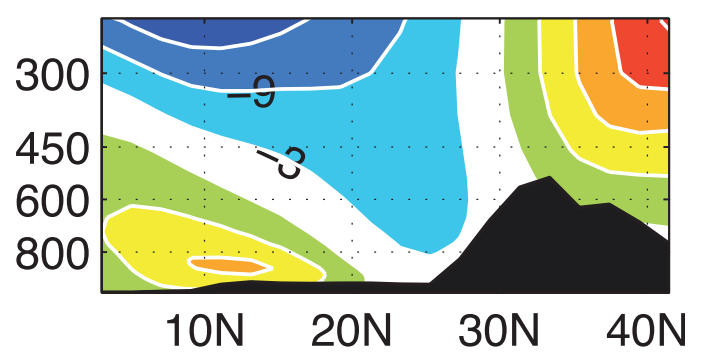

FIG. 1. Zonal winds averaged over the $40^{\circ}-90^{\circ} \mathrm{E}$ longitudinal interval from (left) ERA-40 and (right) AM2.1 simulations, for (a),(d) May, (b),(e) June, and (c),(f) July-August average. Color contour interval is $6 \mathrm{~m} \mathrm{~s}^{-1}$, and the values between -3 and $3 \mathrm{~m} \mathrm{~s}^{-1}$ are not shaded. Black shadings indicate mountain profiles over the longitudinal interval of $40^{\circ}$ and $90^{\circ} \mathrm{E}$.

to be representative of typical mixed layer depths over the north Indian Ocean, and one with a 50-m mixed layer, a value closer to the global average.

In each model integration, the same boundary conditions are used except for topography over South and Central Asia, that is, the Tibetan Plateau. The "fullTibet" experiment is the control experiment, maintaining all the mountains at present-day heights. In the "noTibet" experiment, the entire Tibetan Plateau including the Himalaya is removed (Fig. 2c). To better understand the mechanical effects of topography on the monsoon, we also designed an idealized "narrow-Tibet" experiment. For the narrow-Tibet experiment, the Tibetan Plateau equatorward of $50^{\circ} \mathrm{N}$ is removed, and a latitudinally narrow idealized mountain is imposed between $29^{\circ}$ and $34^{\circ} \mathrm{N}$. Its longitudinal range covers from $45^{\circ}$ to $125^{\circ} \mathrm{E}$ (red contours in Fig. 8). This latitudinally narrow and longitudinally wide idealized mountain is analogous to the narrow mountain in BK10, except that our idealized mountain is located farther northward and extends farther eastward of their location. Steep slopes are specified over the west $\left(45^{\circ}-55^{\circ} \mathrm{E}\right)$ and east $\left(115^{\circ}-125^{\circ} \mathrm{E}\right)$ edges of the idealized mountain, whereas the mountain is flat in the center, from $55^{\circ}-115^{\circ} \mathrm{E}$. The maximum height of this idealized Northern Tibet is limited to $2.5 \mathrm{~km}$. For these no-Tibet and the idealized mountain experiments, climatological mean $U$ winds, $V$ winds, temperature, and geopotential height field obtained from the full-Tibet experiment are used as their initial conditions. Each experiment ran for 22 years, and the last 18 years of the simulation are used for the analysis. These experiments are summarized in Table 1.

Where appropriate, we show comparisons between the model results and observations. Dynamical fields (such as winds) are obtained from the 40-yr European Centre for Medium-Range Weather Forecasts (ECMWF) Re-Analysis (ERA-40; Uppala et al. 2005) archived at the National Center for Atmospheric Research (NCAR)'s 

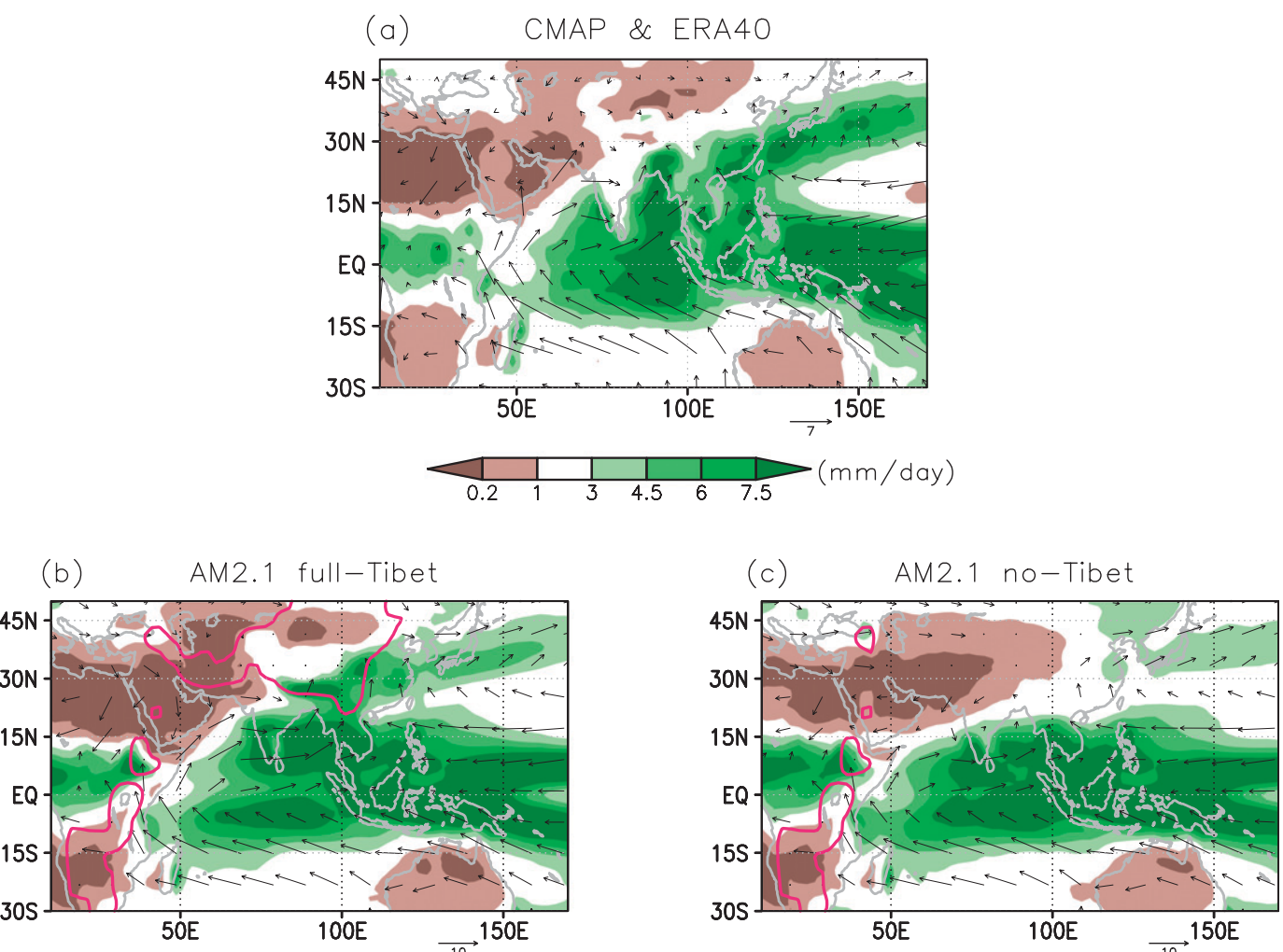

FIG. 2. AMJ precipitation (color contours: $\mathrm{mm} \mathrm{day}^{-1}$ ) and low-level winds at $920 \mathrm{hPa}$ (vectors: $\mathrm{m} \mathrm{s}^{-1}$ ). (a) CMAP precipitation and ERA-40 winds are shown. (b) AM2.1 full-Tibet and (c) AM2.1 no-Tibet experiments are shown. In (b),(c), red contours indicate mountain height in AM2.1. Mountains higher than $1000 \mathrm{~m}$ are contoured.

Data Support Section (http://www.cgd.ucar.edu/cas/ catalog/ecmwf/era40). These data consist of monthly means for $256 \times 128$ regular Gaussian grids at T-85 spectral truncation and 23 pressure levels spanning September 1957 to August 2002. Precipitation is from the Climate Prediction Center (CPC) Merged Analysis of Precipitation (CMAP; Xie and Arkin 1997). The CMAP data consist of monthly means at a horizontal resolution of $2.5^{\circ} \times 2.5^{\circ}$ spanning January 1979 to December 2005.

\section{Zonally asymmetric monsoon onset}

Before monsoon onset, westerlies over the Tibetan Plateau are still significant and therefore likely to generate Rossby waves in the subtropics. Because uppertroposphere easterlies have limited meridional extent before the monsoon onset (Figs. 1a,d), Rossby waves induced by the Tibetan Plateau might be able to propagate equatorward and thereby affect tropical overturning circulations (Bordoni and Schneider 2008). Observations consistently indicate that the subtropical jet remains over the Southern Tibetan Plateau and the Indian subcontinent, before shifting northward in the early June (Yin 1949; Hahn and Manabe 1975). In May, the center of the westerly jet is still located over the Tibetan Plateau, and its magnitude is still substantial, in both the ERA-40 (Fig. 1a) and in AM2.1 simulations (Fig. 1d). Overall, the seasonal evolution of westerly wind structure simulated by AM2.1 is consistent with ERA-40. Also, Fig. 2 shows that AM2.1 simulates the Somali jet reasonably well, which is in good qualitative agreement with the ERA-40 data, despite being 30\% stronger. On the other hand, the Mei-yu front in East Asia simulated by AM2.1 is weaker than the observation by $30 \%-50 \%$.

\section{a. Downstream preference of rainfall}

The CMAP rainfall over the tropical Indian Ocean exhibits a zonally asymmetric pattern in AMJ, with higher rainfall downstream of the Tibetan Plateau (e.g., Bay of Bengal and South China) than upstream (e.g., Pakistan, Arabian Peninsula, and Arabian Sea; Fig. 2a). The rainfall pattern simulated by AM2.1 indicates a similar downstream preference of monsoon rainfall (Fig. 2b), with larger rainfall magnitudes over the Bay of Bengal and South China than the Arabian Sea. This zonally asymmetric monsoon onset was also discussed by Hsu et al. (1999), where observation-based daily 
TABLE 1. AM2.1 design of experiments.

\begin{tabular}{lll}
\hline \hline Experiments & \multicolumn{1}{c}{ Descriptions } & Figures \\
\hline Full-Tibet & Control experiment with full topography & Figs. $2 \mathrm{~b}$ and 3 \\
No-Tibet & Entire Tibetan Plateau east of $45^{\circ} \mathrm{E}$ is reduced by $95 \%$. & Fig. 2c \\
Narrow-Tibet & On the no-Tibet boundary condition, a latitudinally narrow & Fig. 8 \\
& 2.5 -km-height idealized mountain is imposed between $29^{\circ}$ & \\
& and $34^{\circ} \mathrm{N}$. Its longitudinal range covers from $45^{\circ}$ to $125^{\circ} \mathrm{E}$. & \\
& Steep slopes are specified over the west $\left(45^{\circ}-55^{\circ} \mathrm{E}\right)$ and east & $\left(115^{\circ}-125^{\circ} \mathrm{E}\right)$ edges of the idealized mountain, whereas the \\
& mountain is flat in the center, from $55^{\circ}$ to $115^{\circ} \mathrm{E}$. & \\
\hline
\end{tabular}

outgoing longwave radiation (OLR) and diabatic heating were used to infer the moist convection.

In the absence of the Tibetan Plateau, the zonally asymmetric rainfall pattern disappears and the strong Somali jet weakens (Fig. 2c). Rainfall over the Bay of Bengal and South China decreases substantially, leading to a more zonally symmetric intertropical convergence zone (ITCZ). The reduced moist convection over the Bay of Bengal is accompanied by a weakening of the Somali jet, suggesting that the low-level convergence over the Bay of Bengal is tied to the large-scale monsoonal flow. The anomalous monsoon rainfall and lowlevel winds calculated from the differences between the full-Tibet and no-Tibet experiments clearly indicate earlier monsoon rainfall downstream of the Tibetan Plateau (Fig. 3a). Downstream rainfall increase is not limited to the Bay of Bengal and South China but extends to the southern part of Korea and Japan, in association with the strengthening of the Mei-yu front. The presence of the Tibetan Plateau dramatically strengthens the 920-hPa westerly winds up to $7-10 \mathrm{~m} \mathrm{~s}^{-1}$ over the Somali coast, Arabian Sea, and the Indian subcontinent. The stronger monsoon circulation is tied to the basinwide strengthening of surface latent heat flux (Fig. 3b), which is spatially coherent with stronger surface winds (contours in Fig. 3b). This active wind-induced surface heat exchange (WISHE; Emanuel 1987; Neelin et al. 1987) might be able to provide a positive feedback on the monsoonal circulation strength (Boos and Emanuel 2009; Boos 2008).

\section{b. Rodwell-Hoskins mechanism}

Another notable impact of the Tibetan Plateau on the monsoon is the strengthening of the zonally asymmetric circulation pattern associated with Rossby waves. As shown in the previous section, monsoon rainfall increases considerably downstream of the Tibetan Plateau in the presence of strong westerly winds. Diabatic heating associated with the downstream moist convection might trigger Rossby waves, which contributes to decreasing rainfall upstream. Figure 4 a shows the anomalous pressure velocity (omega) in AMJ calculated from the differences between the full-Tibet and no-Tibet experiment (here, we flipped the sign, so positive values imply upward motions). The presence of the Tibetan Plateau strengthens upward motions by $15 \%-25 \%$ downstream of the mountains, whereas it enhances subsidence upstream of the mountain (e.g., Pakistan, Afghanistan, and Arabian Peninsula), which is highly suggestive of Rossby wave dynamics (Rodwell and Hoskins 2001; Chou et al. 2001). This downstream diabatic heating-induced upstream subsidence effect should be differentiated from the mechanically driven descent equatorward of the Tibetan Plateau before the monsoon onset (Sato and Kimura 2007). While Sato and Kimura (2007) focused on the descending motion south of the Tibetan Plateau, we focus on the descending motion west (i.e., upstream) of the Tibetan Plateau. We speculate that the generation of Rossby waves and the associated upstream subsidence would be a dominant mode of response to a localized diabatic heating in the subtropics (Rodwell and Hoskins 2001). We could not find any clear signal suppressing the monsoon rainfall equatorward of the Tibetan Plateau before the monsoon onset, which was suggested by Sato and Kimura (2007).

A zonally asymmetric circulation pattern in the Northern Hemisphere summer is typically associated with Sverdrup balance $[\beta v \approx f(\partial \omega / \partial p)$; Kang and Held 1986; Rodwell and Hoskins 2001]. The moist static energy (MSE) flux, integrated from the surface to $600 \mathrm{hPa}$, $\int_{\mathrm{sfc}}^{600}(v h) d p / g$, is calculated both for the full-Tibet and no-Tibet experiment and the differences between these two are presented in Fig. $4 \mathrm{~b}$. Here, $h$ represents the MSE, and $d p / g$ is the air mass of individual vertical level. We choose $600 \mathrm{mb}$ as the characteristic depth of largescale flow around topography is known to be well above the steering level (around $700 \mathrm{hPa}$ ) in the subtropics $\left(20^{\circ} \sim 30^{\circ} \mathrm{N}\right.$; Takahashi and Battisti 2007b), and we wanted to capture this flow as well. While the MSE flux is strongly negative upstream of the Tibetan Plateau (e.g., Pakistan, Afghanistan, and Arabia Peninsula), it increases to positive values downstream of the Tibetan Plateau. This poleward flow sweeps the MSE from the Bay of Bengal, South China 
(a) AMJ Precip (Tibet-noTibet)

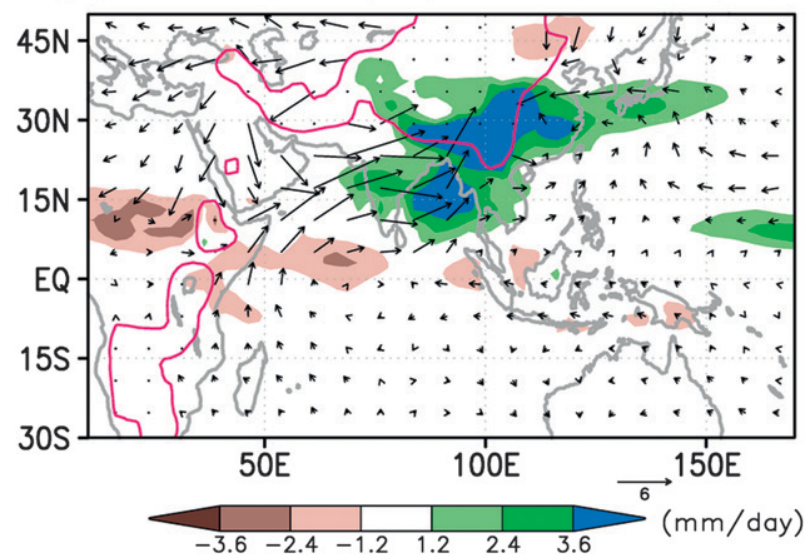

(b) AMJ LHFLX (Tibet-noTibet)

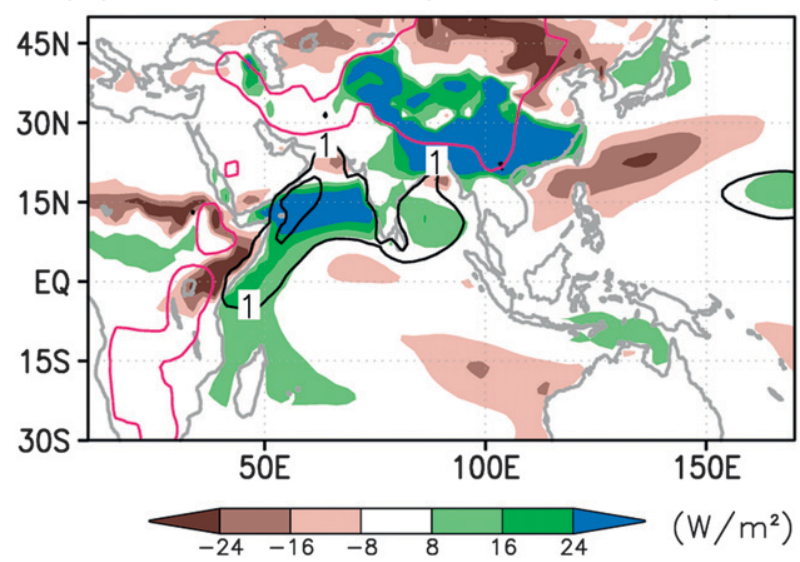

FIG. 3. AMJ anomalous precipitation, surface wind speed, and surface latent heat flux calculated from the differences between fullTibet and no-Tibet. (a) Precipitation (color contours: $\mathrm{mm} \mathrm{day}^{-1}$ ) and 920-hPa winds (vectors: $\mathrm{m} \mathrm{s}^{-1}$ ) are shown. (b) Surface latent heat flux (color contours: $\mathrm{W} \mathrm{m}^{-2}$ ) and surface wind speeds (line contours: $\left.\mathrm{m} \mathrm{s}^{-1}\right)$ are shown.

Sea, all the way into the subtropical western North Pacific, which is likely to strengthen the Mei-yu front.

This result suggests that the atmosphere downstream of the Tibetan Plateau experiences vertical stretching $[(\partial \omega / \partial p)>0]$, driving the monsoon-like northward flow (Gill 1980). These results raise the question as to what causes vertical stretching downstream of the Tibetan Plateau. Previous studies externally imposed diabatic heatings in a dry AGCM (Rodwell and Hoskins 2001) or vertical stretching in a barotropic model (Kang and Held 1986) to examine the response of large-scale circulation to the vertical stretching in the subtropics. While successfully reproducing important features of the large-scale summertime circulations, these studies do not provide insights on what controls the structure and distribution of

\section{(a) AMJ Omega (Tibet-noTibet)}

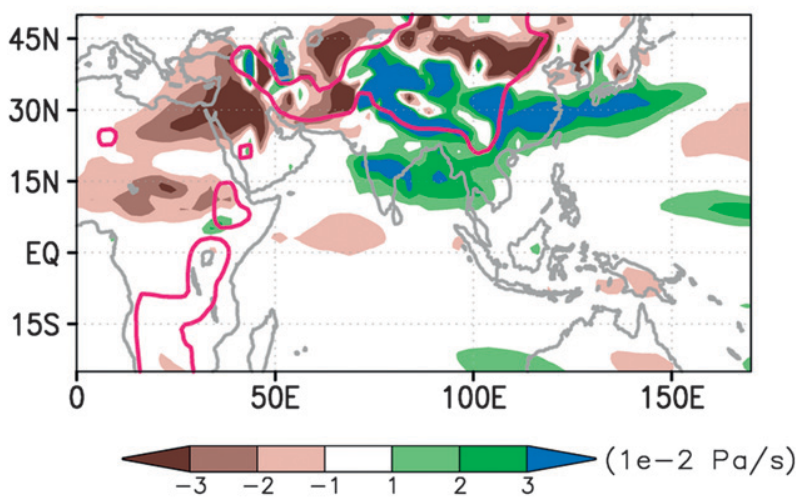

(b) AMJ MSE flux (Tibet-noTibet)

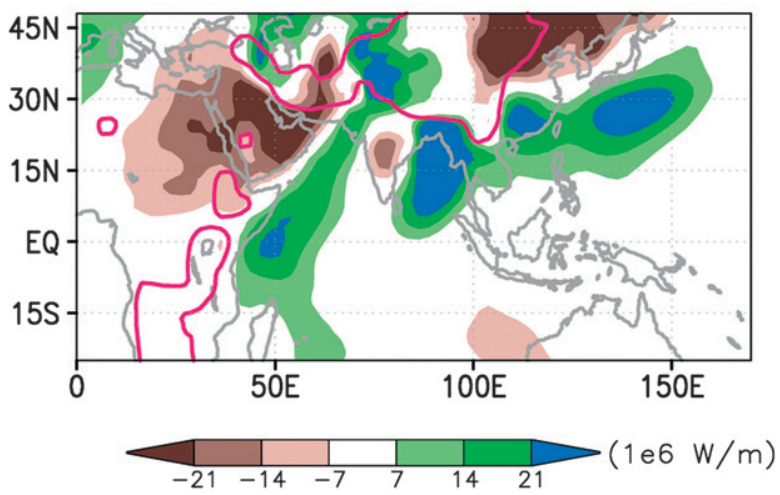

FIG. 4. AMJ anomalous (a) pressure velocity $\left(-10^{-2} \mathrm{~Pa} \mathrm{~s}^{-1}\right)$ and (b) meridional MSE flux $\left(10^{6} \mathrm{~W} \mathrm{~m}^{-1}\right)$ calculated from the differences between the full-Tibet and no-Tibet (full-Tibet minus no-Tibet). The meridonal MSE flux, Vh was integrated from the surface to $600 \mathrm{hPa}$. In (a), brown colors indicate anomalous largescale subsidence and vice versa. In (b), brown colors indicate negative meridional MSE flux associated with anomalous northerly winds and vice versa.

the diabatic heating (or vertical stretching) itself. Rodwell and Hoskins (2001) provide a qualitative description of the stationary wave response induced by a north-southelongated mountain ranging from tropics to midlatitudes such as the Andes; meridional displacements of westerly and easterly winds forced by the outcrop of surface isentropes produce downstream (upstream) stretching (shrinking) from simple considerations of how adiabatic flow interacts with topography.

The schematic of Rodwell and Hoskins (2001) is not applicable to east-west-oriented narrow mountains, such as the narrow-Tibet in BK10, where topography might not be effective at significantly displacing winds meridionally. Thus, it might be argued that the thermal insulator effect, rather than the mechanical effect, might 
be responsible for enhancing moist convection over the Bay of Bengal in the presence of the east-west-oriented narrow mountains (Molnar et al. 2010). While we do not exclude a possible role for the thermal insulator effect, we will later demonstrate with AM2.1 and a dry atmospheric model that east-west-oriented narrow mountains can produce downstream convergence (i.e., vertical stretching).

\section{Mechanically driven downstream convergence}

Because diabatic heating can be initiated both mechanically (mechanically driven horizontal convergence) and thermally (moist convection where subcloud-layer entropy is high), there is no easy way to distinguish between the mechanical effect from the thermal insulator effect. In section $4 \mathrm{a}$, we indirectly infer the mechanical effect by examining the seasonally varying impact of the Tibetan Plateau on monsoon circulation strength. In section $4 \mathrm{~b}$, we revisit the possible Tibetan Plateau heating impact by examining the dry static stability. In section $4 c$, we try to find a direct evidence of mechanically driven downstream convergence by performing idealized experiments in AM2.1.

\section{a. Seasonally varying impact of the Tibetan Plateau on the monsoon}

As discussed above, westerly winds over the Tibetan Plateau are quite significant before monsoon onset, but they shift northward, with easterlies developing in the equatorial upper troposphere during July-September (JAS). The AM2.1 simulated July-September mean climate may well represent the Asian monsoon associated with these weakened westerly winds (Fig. 5a). Unlike the AMJ mean climate (Fig. 2b), which shows a well-developed Mei-yu front over East Asia, the Mei-yu front almost disappears in JAS (Fig. 5a). The monsoon rainfall over Northern India and Pakistan gets substantially stronger in JAS, whereas the signal of downstream preference of rainfall, particularly over South China, almost disappears.

Unlike AMJ (Fig. 3), the Tibetan Plateau has very limited impact on the monsoonal circulation strength in July-September (Figs. 5b,c). In the presence of the Tibetan Plateau, JAS monsoon rainfall increases over the southern edge of the Tibetan Plateau, and the 920-hPa winds over the Arabian Peninsula increase by $4-8 \mathrm{~m} \mathrm{~s}^{-1}$. However, these rainfall and wind responses are quite localized. Unlike AMJ, the change to the JAS largescale surface evaporation over the North Indian Ocean to the removal of the Tibetan Plateau is relatively small (Fig. 5c). Even in the absence of the Tibetan Plateau, the monsoon circulation becomes progressively stronger and

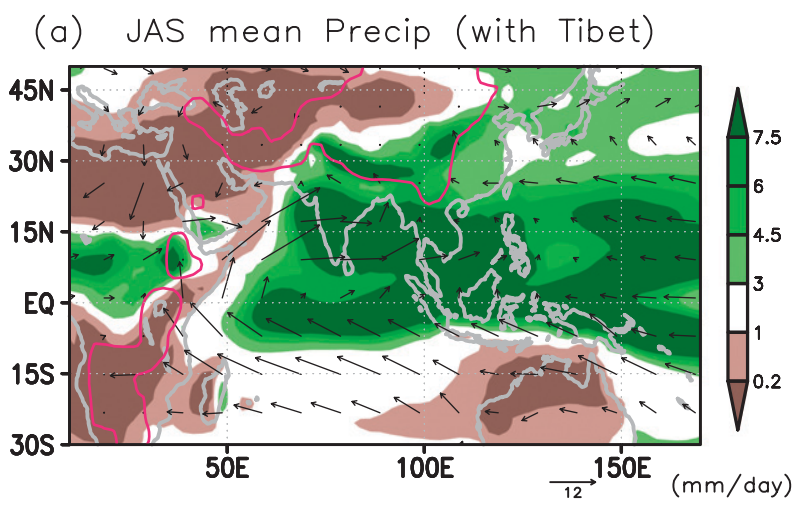

(b) JAS Precip (Tibet-noTibet)

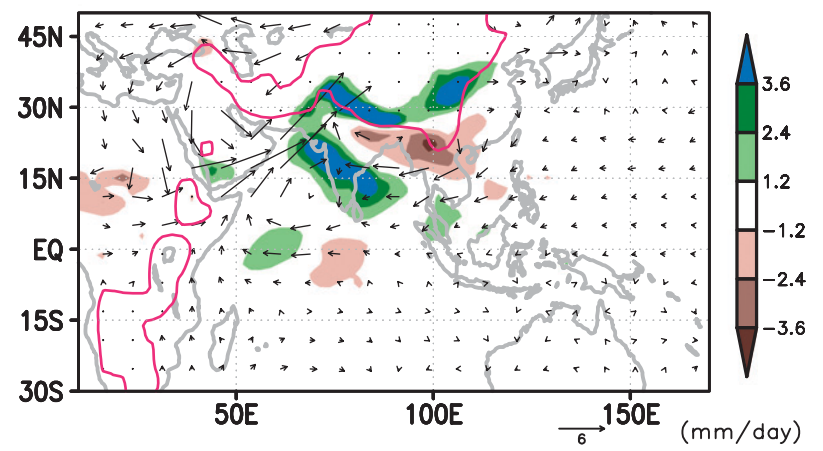

(c) JAS LHFLX (Tibet-noTibet)

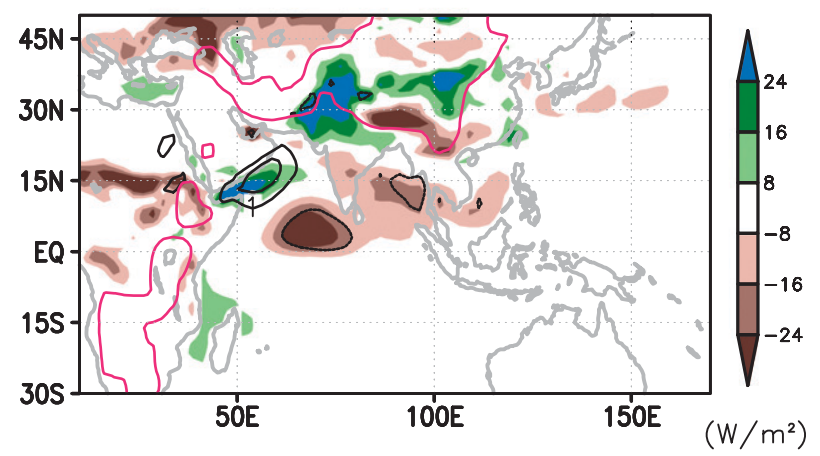

FIG. 5. (a) JAS climate-mean precipitation (color contours: $\mathrm{mm} \mathrm{day}^{-1}$ ) and low-level winds at $920 \mathrm{hPa}$ (vectors: $\mathrm{m} \mathrm{s}^{-1}$ ) simulated by AM2.1. JAS anomalous (b) precipitation (color contours: mm day ${ }^{-1}$ ) with $920-\mathrm{hPa}$ winds (vectors: $\mathrm{m} \mathrm{s}^{-1}$ ) and (c) surface latent heat flux (color contours: $\mathrm{W} \mathrm{m}^{-2}$ ) with surface wind speeds (line contours: $\mathrm{m} \mathrm{s}^{-1}$ ) calculated from the differences between fullTibet and no-Tibet.

reaches comparable strength during the mature phase. Our result is somewhat consistent with the classic study by Hahn and Manabe (1975), which found that the monsoon gradually progresses northward in the absence of the Tibetan Plateau.

The seasonally varying impact of the Tibetan Plateau on monsoon circulation strength is demonstrated more quantitatively in Fig. 6, which shows monthly-mean fractional changes of low-level wind speed over the 


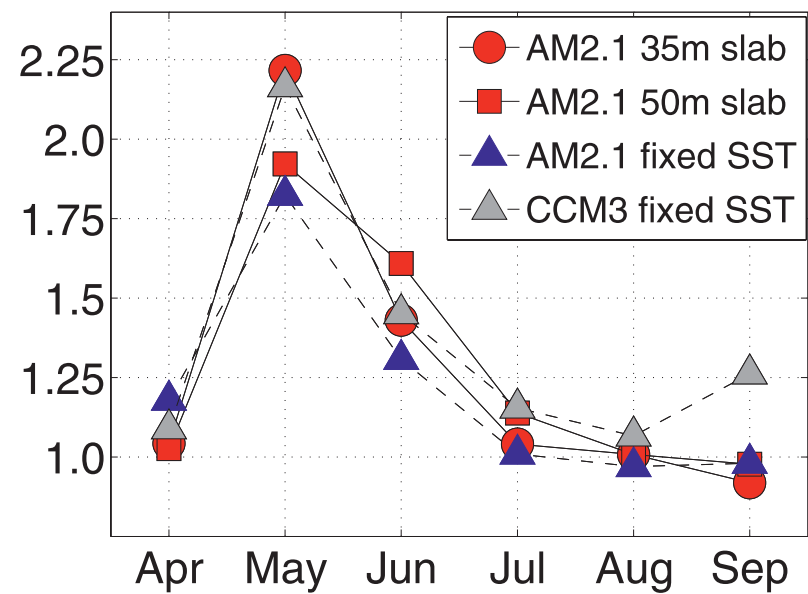

FIG. 6. Fractional changes of low-level wind speed (900-970-hPa average) over the North Indian Ocean and subcontinent of India, calculated from the ratio between Tibet and no-Tibet experiments. Monthly-mean low-level wind speeds are averaged over the $45^{\circ}$ $90^{\circ} \mathrm{E}$ and $5^{\circ}-33^{\circ} \mathrm{N}$ box before computing ratios for each individual month. In April, the presence of the Tibetan Plateau greatly affects the direction of winds, not the wind speed.

North Indian Ocean and the Indian subcontinent, calculated from the ratio between full-Tibet and no-Tibet experiments (i.e., full-Tibet/no-Tibet). The low-level wind speeds are calculated by vertically averaging the wind speed from 970 to $900 \mathrm{hPa}$ at each grid cell, and horizontally averaging over the $45^{\circ}-90^{\circ} \mathrm{E}$ and $8^{\circ}-33^{\circ} \mathrm{N}$ box. The Tibetan Plateau strengthens monsoonal winds by $170 \%-230 \%$ in May, but the impact rapidly diminishes thereafter. In April, the Tibetan Plateau changes the direction, but not the magnitude, of the low-level winds from northeasterlies to weak southwesterlies over the North Indian Ocean. Thus, the actual impact of the Tibetan Plateau on monsoon circulation during April is more substantial than what is suggested in Fig. 6. During and after the mature phase of the monsoon (JAS), the monsoon strength remains largely unaffected by the presence of the Tibetan Plateau. These results are robust to changes in mixed layer depths or to choice of prognostic or fixed SSTs. We have performed analogous full-Tibet and noTibet experiments with a different AGCM, the NCAR Community Climate Model version 3 (CCM3; Kiehl et al. 1998) with T42 resolution and climatologically fixed SSTs. We find that CCM3 exhibits results are qualitatively similar to those obtained with AM2.1 (gray triangle in Fig. 6). ${ }^{1}$

\footnotetext{
${ }^{1}$ In general, our results are not very sensitive to changes in the horizontal averaging region $\left(45^{\circ}-90^{\circ} \mathrm{E}\right.$ and $\left.8^{\circ}-33^{\circ} \mathrm{N}\right)$, but the fractional changes become somewhat higher in July and August when the averaging box region is chosen to only cover the Arabian Sea area. As Fig. 5 shows, low-level winds over a localized area in the Arabian Sea get stronger during JAS in the presence of the Tibetan Plateau.
}

Our results differ from a CGCM study by Abe et al. (2003), in which the June-August large-scale monsoonal winds and precipitation gradually increase with a gradual uplift of the Tibetan Plateau. However, the resolution of the atmospheric model used in Abe et al. (2003) is coarser than the one used here $\left(5^{\circ}\right.$ longitude $\times 4^{\circ}$ latitude horizontally, with 15 vertical layers). This resolution is even coarser than T31. Similarly, Hahn and Manabe (1975) used a coarse-resolution AGCM, with 11 vertical levels. They found that the northward monsoonal flow cannot progress beyond the central India in the absence of the Tibetan Plateau. It seems that low-resolution AGCMs simulate much stronger response of the South Asian monsoon to the presence of the Tibetan Plateau.

Because the impact of the Tibetan Plateau on monsoon circulation strength is essentially limited to the early monsoon season, the seasonally accumulated monsoon rainfall is not dramatically affected by the presence of the Tibetan Plateau. In AM2.1, June-September (JJAS) averaged accumulated rainfall over the Indian subcontinent and the Bay of Bengal $\left(70^{\circ}-100^{\circ} \mathrm{E}\right.$ and $\left.18^{\circ}-33^{\circ} \mathrm{N}\right)$ is about $20 \%-60 \%$ higher in the full-Tibet than in the no-Tibet experiment (not shown). These differences are much higher than the maximum interannual variability of Indian monsoon rainfall of present climate, which is about 10\% (Gadgil 2003; Molnar et al. 2010).

\section{$b$. Any potential role of the plateau heating?}

The classical theory of the Tibetan Plateau heating (Yeh et al. 1957; Flohn 1957; Luo and Yanai 1984; Webster et al. 1998) has been recently challenged by BK10. For instance, in one of their numerical experiments, where the surface albedo over the central Tibetan Plateau is set to unity (albedo $=1.0$ ), they found that surface heat fluxes from the Plateau exert a local effect on precipitation patterns near the mountains but have a negligible impact on the monsoon circulation strength.

To examine the potential role of surface heating in our experiments, here we use the dry static stability $[(g / \theta)(d \theta / d z)]$, where $\theta$ refers to potential temperature. As Sato and Kimura (2007) noted, daily average temperature in India exceeds $30^{\circ} \mathrm{C}$ before the monsoon onset in May and June. While this near-surface heating might destabilize the vertical temperature profile, often producing low-level convergence, relatively low dry static stability does not necessarily imply a favorable preconditioning for low-level convergence. Instead, relatively low dry static stability often results from adiabatic warming associated with strong descending motion (Charney 1975).

Figure 7a shows May-June dry static stability calculated from the no-Tibet simulation. Following Frierson and Davis (2011), we compute $(g / \theta)(d \theta / d z)$ at each individual vertical level and then calculate the mass-weight 
(a) May-June Static Stability (noTibet)

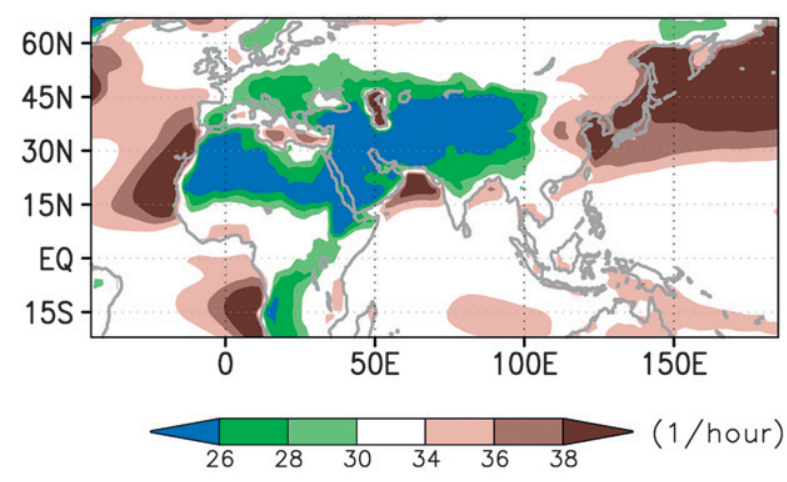

(b) anomalous Static Stability (Tibet-noTibet)

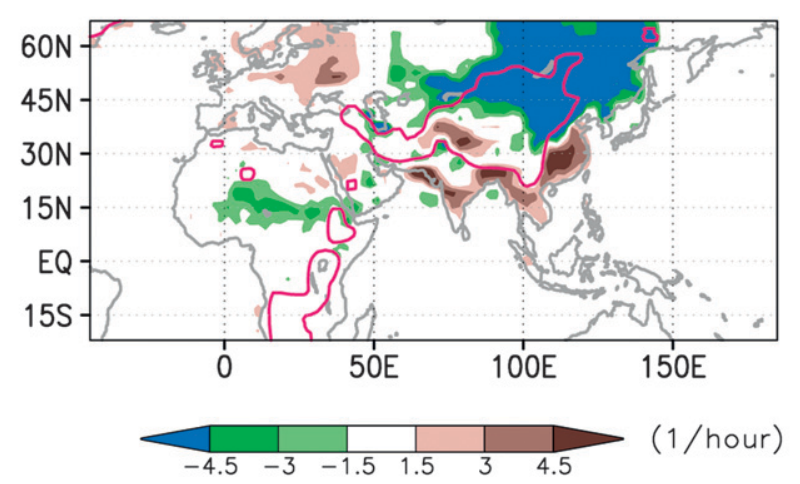

FIG. 7. (a) May-June dry static stability (unit: $\mathrm{h}^{-1}$ ) averaged from the surface to $400 \mathrm{hPa}$, and (b) May-June anomalous lowlevel (from the surface to the 0.5 -sigma level) dry static stability calculated from the differences between full-Tibet and no-Tibet. Mountains higher than $1000 \mathrm{~m}$ are contoured (red color).

average from the surface to $400 \mathrm{hPa}$. The most notable pattern in Fig. $7 \mathrm{a}$ is the contrast of dry static stability between the landmasses and the ocean, resulting from the strong land-sea thermal contrast. This result is somewhat consistent with Fig. 1c of Frierson and Davis (2011). Dry static stability over land is a minimum in June (not shown), probably because the incoming solar radiation is a maximum over the subtropical land surface then. The dry static stability over the South Asian monsoon region rather slightly increases during the mature phase of the monsoon (July-August) because latent heat release from monsoonal rainfall tends to saturate the lapse rate.

Figure $7 \mathrm{~b}$ shows the anomalous low-level dry static stability calculated from the difference between the fullTibet and no-Tibet experiments. For Fig. 7b, we calculate the mass-weight average from the surface to the 0.5 sigma level both for the full-Tibet and no-Tibet experiments to avoid potential artifacts due to the presence (or absence) of elevated topography. The dry static stability does not change much over the subtropical Tibetan Plateau, suggesting that the Plateau heating may have negligible effects on destabilizing the atmosphere. Furthermore, unlike the classic study by Hahn and Manabe (1975), where free tropospheric temperature increases in the presence of the Tibetan Plateau, free tropospheric temperature decreases in the AM2.1 (not shown). Interestingly, the dry static stability substantially decreases over the northeastern side of the Tibetan Plateau. It is probably because the topographically forced stationary waves produce northwesterly flow over the East Asian midlatitudes (see the negative MSE flux over the East Asian midlatitudes in Fig. 4b), which might dry out lowlevel moisture and thereby suppressing the midtroposphere latent heating.

\section{c. Mechanical control on the downstream convergence in AM2.1}

Because westerly wind speeds over the Tibetan Plateau are closely tied to the meridional temperature gradient, both dynamical and thermal insulator effects may coherently decrease during the course of monsoon development. To better elucidate the mechanical effect, and to isolate it from the thermal insulator effect, we designed a narrow-Tibet experiment, which mimics the Himalayalike idealized topography of BK10 (hereafter "idealized Tibet"). In BK10, the Bay of Bengal is located right downstream of the idealized Tibet. Because mechanically driven pressure disturbances can immediately interact with the moist convection over the Bay of Bengal, it is hard to distinguish between the mechanical effect and the thermal insulator effect in the idealized Tibet experiment of BK10. Unlike the idealized Tibet of BK10, we imposed downslope of our narrow-Tibet over far-east inland areas, particularly over the East China. The narrowTibet covers the $45^{\circ}-125^{\circ} \mathrm{E}$ longitudinal range, which is longitudinally wider than the real Tibetan Plateau, and the $29^{\circ}-34^{\circ} \mathrm{N}$ latitudinal range, which is narrower than the idealized Tibet of BK10. Since this idealized mountain is still embedded in the westerlies, the mechanical effect should still be evident. However, our narrow-Tibet is located slightly northward than the idealized Tibet of BK10, particularly over the Eastern India areas (near Bay of Bengal), which presumably alters the ventilation effect, since Bay of Bengal is now less effectively "protected" from advection of low MSE air from the extratropics.

Figure 8 shows the response of low-level winds and precipitation to the narrow-Tibet calculated from the differences between the narrow-Tibet and no-Tibet experiments. The downstream preference of rainfall discussed in the previous sections is still evident. It is interesting to note that the precipitation rate is higher over the mountain range than on its equatorward flank, suggesting that 


\section{(a) AMJ Precip (Tibet-noTibet)}

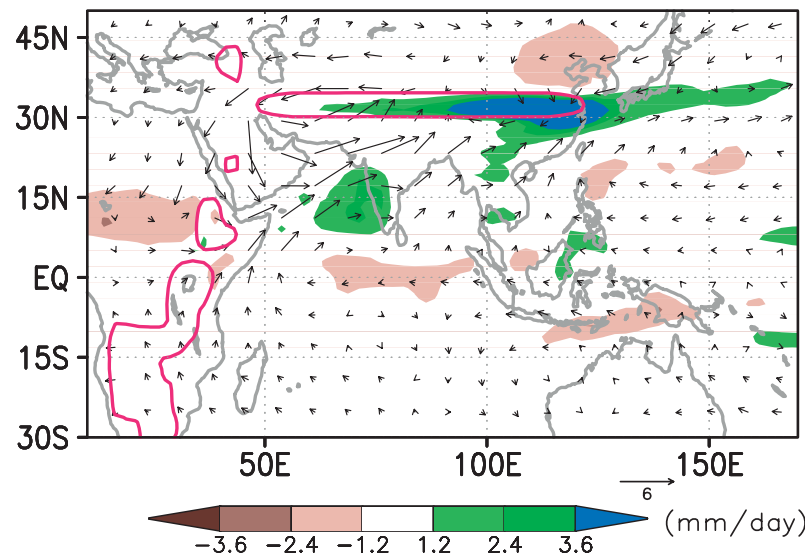

(b) AMJ LHFLX (Tibet-noTibet)

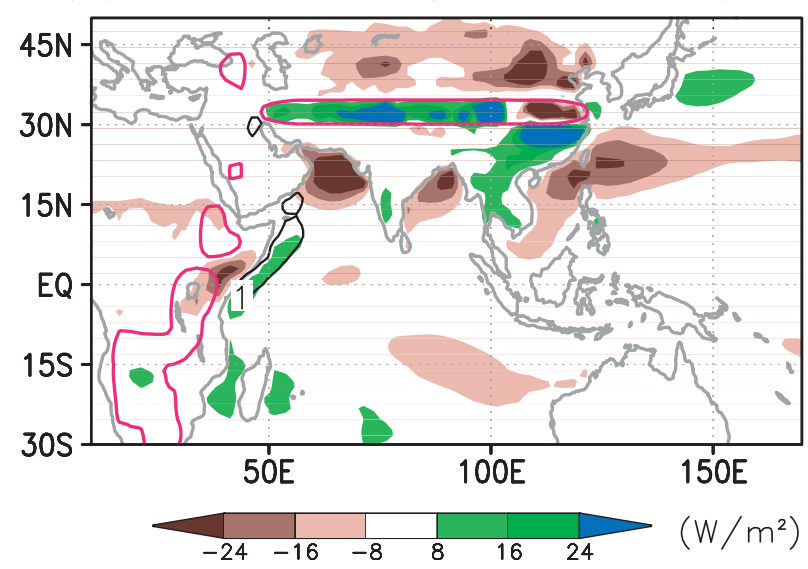

FIG. 8. AMJ anomalous precipitation, surface wind speed and surface latent heat flux calculated from the differences between the idealized narrow-Tibet and no-Tibet. (a) precipitation (color contours: $\mathrm{mm} \mathrm{day}^{-1}$ ) and $900 \mathrm{hPa}$ winds (vectors: $\mathrm{m} \mathrm{s}^{-1}$ ). (b) surface latent heat flux (color contours: $\mathrm{W} \mathrm{m}^{-2}$ ) and surface wind speeds (contours: $\mathrm{m} \mathrm{s}^{-1}$ ). Mountains higher than $1000 \mathrm{~m}$ are contoured (red color).

the thermal insulator effect may not be directly applicable to this narrow-Tibet case. Unlike the full-Tibet case, downstream moist convection in narrow-Tibet is not accompanied by the basinwide strengthening of monsoonal surface winds or surface latent heat flux (cf. Figs. $3 \mathrm{~b}$ and $8 \mathrm{~b}$ ). Surface winds increase by $1-1.5 \mathrm{~m} \mathrm{~s}^{-1}$ over the Arabian coast but are quite weak in other areas. It is probably because the area of downstream convergence in the narrow-Tibet case is far east, so it is out of the equatorial Rossby radius of deformation. Alternatively, this might be explained by the fact that the area of downstream convergence is farther away from the ocean.

The results from the narrow-Tibet experiment, which arguably allows us to expose more clearly the mechanical response to the Plateau, raise the question as to what extent the downstream preference of monsoonal rainfall might be mechanically driven. It is plausible that this downstream moist convection is a linear stationary wave response to the mountain slope, such as low-level cyclonic motions (Held et al. 2002; Cook and Held 1992). However, it is also possible that the downstream convergence may not be related to the planetary-scale potential vorticity conservation. Topography-forced vertical motions interacting with the momentum balance may alter the horizontal divergence field (Smith 1980).

\section{Downstream convergence in a dry dynamical core}

The idealized north Tibet experiment suggests a stronger role of mechanical effect relative to the thermal insulator effect on the downstream convergence, but the genesis mechanism for this feature is thus far unknown. In particular, it is unclear how an east-west-oriented narrow mountain can produce downstream convergence without substantially altering meridional winds. To better understand the mechanical effect, we used an idealized dry GCM - a spectral dynamical core developed at GFDL.

\section{a. Idealized dry model}

The dry model integrates the primitive equations on the sphere with the spectral transform method in the horizontal T85 resolution and with 30 unevenly space sigma levels in the vertical. Radiative cooling is represented by Newtonian relaxation to a prescribed zonalmean radiative equilibrium temperature profile (i.e., Held-Suarez forcing; Held and Suarez 1994). We added a Gaussian mountain in the model by elevating the surface geopotential height. The Gaussian mountain is centered at $32^{\circ} \mathrm{N}$ with $24^{\circ}$ longitudinal half-width and $6^{\circ}$ latitudinal half-width, which is comparable to the narrow Tibet in BK10. Note that if the latitudinal halfwidth is further decreased, Gibbs oscillations start appearing in the convergence-divergence fields, which is a well-known issue with spectral models (Navarra et al. 1994). The maximum height of the mountain is either 2.5 or $4 \mathrm{~km}$. A set of experiments was performed by varying the equator-to-pole equilibrium temperature gradient $\left(\Delta T_{\text {eq }}\right)$, characterized by a hemispherically symmetric profile. To test the robustness of the model results, we also performed experiments with a hemispherically asymmetric radiative equilibrium temperature profile. For all these experiments, constant static stability is imposed at individual latitude, which mimics the earth's static stability in the troposphere.

Because we aim at understanding the general process of downstream convergence, imposing the exact shape 
of the Tibetan Plateau is not essential to these simulations. Instead, as Held et al. (2002) noted, the background zonal wind structure would be a far more important factor for realistically simulating the topography-forced stationary waves. While this idealized dry model might be able to reasonably mimic the zonal wind structure in boreal spring, the diabatic heating field can be quite different from observations. In this section, we mostly focus on the outputs from the hemispherically symmetric temperature forcing with a Gaussian mountain in the subtropics. In the case when a $30-$ or $45-\mathrm{K} \Delta T_{\text {eq }}$ is specified, westerly wind speeds in the dry model are comparable to the observed wind speeds in April or May. Low-level divergence consistently occurs along the latitudinal band where the mountain is located (it is in the subtropics) regardless of the varying temperature gradient.

\section{b. Results}

Here, we focus on the results from the hemispherically symmetric, $\Delta T_{\mathrm{eq}}=30 \mathrm{~K}$ with a mountain imposed in the subtropics. We test the robustness of our results by varying the height of the mountains from 2.5 to $4 \mathrm{~km}$; we find that the results are not very sensitive to the heights over this range. ${ }^{2}$ Results from the $\Delta T_{\mathrm{eq}}=45 \mathrm{~K}$ (not shown) look qualitatively consistent with those from the $\Delta T_{\text {eq }}=30-\mathrm{K}$ experiments. Figure 9a shows zonal-mean westerly winds with the $2.5-\mathrm{km}$-height mountain profile. The westerly wind speed in the upper troposphere $(300 \mathrm{hPa})$ is about $20-28 \mathrm{~m} \mathrm{~s}^{-1}$, centered at around $35^{\circ} \mathrm{N}$. The zonal wind structure in the dry model is in good qualitative agreement with the observed zonal winds over the Tibetan Plateau in April or May.

Figure 10a shows the lower-level eddy relative vorticity response to the mountain, where the eddy refers to the deviation from the zonal mean. Warm (cool) colors indicate cyclonic (anticyclonic) relative vorticity. Downstream cyclonic motions, a typical linear response of stationary waves (Cook and Held 1992; Held et al. 2002), do not occur, suggesting that the linear theory is not applicable to a mountain in the subtropics, particularly in the presence of a weak meridional temperature gradient. We were able to observe the typical linear response of stationary waves in the case when the Gaussian mountain is located in midlatitudes (around $40^{\circ}-50^{\circ} \mathrm{N}$ ) with a fairly strong meridional equivalent temperature gradient, larger than $60 \mathrm{~K}$ (not shown). Figure 10b shows the lower-level convergence integrated from the surface to the 0.9 sigma level. Because of the equatorial warming,

\footnotetext{
${ }^{2}$ Transition from linear to nonlinear stationary wave responses to increased mountain height, particularly from 2 to $4 \mathrm{~km}$ (Cook and Held 1992), does not appear in our idealized dry model.
}

(a) zonal winds of dry model $(\mathrm{dT}=30)$

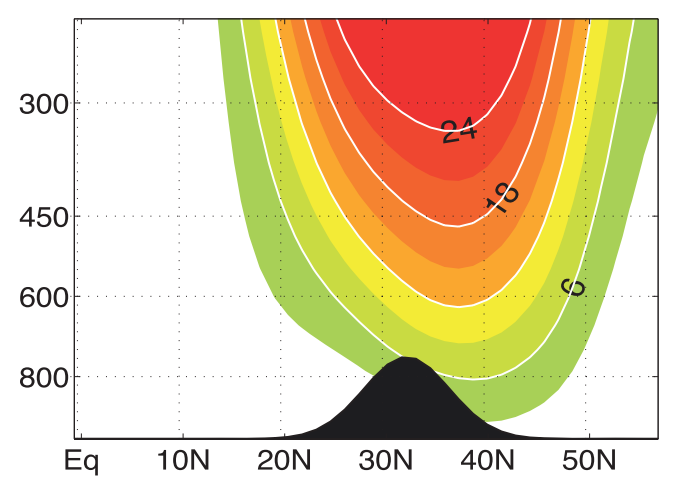

(b) eddy U-winds and divergence

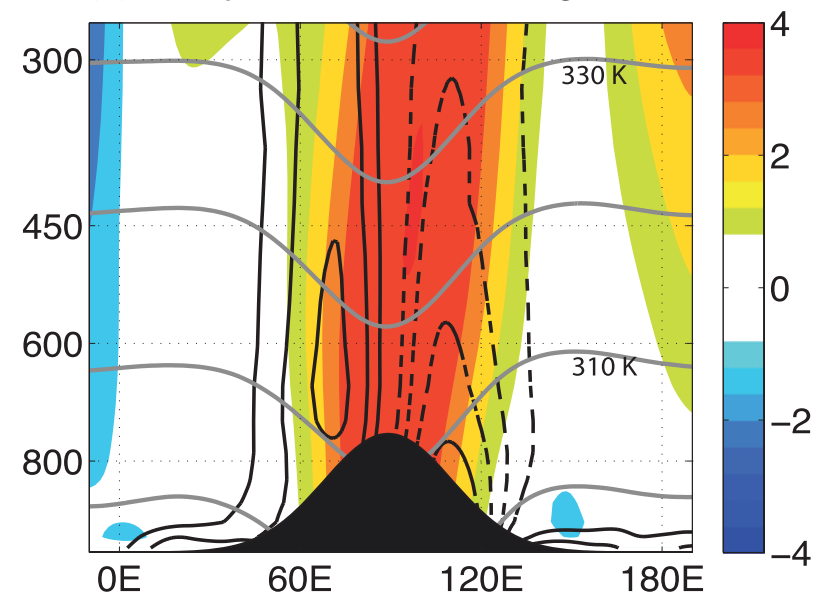

FIG. 9. (a) Zonal-mean westerly winds (color contours, $\mathrm{m} \mathrm{s}^{-1}$ ) with the interval of $3 \mathrm{~m} \mathrm{~s}^{-1}$. Values between -3 and $3 \mathrm{~m} \mathrm{~s}^{-1}$ are not shaded. (b) Eddy westerly wind speed (color contours; $\mathrm{m} \mathrm{s}^{-1}$ ) and divergence (black contour; $\mathrm{s}^{-1}$ ) averaged between $28^{\circ}$ and $32^{\circ} \mathrm{N}$, where the Gaussian mountain is located. Solid and dashed lines indicate divergence and convergence, respectively, with contour interval of $0.4 \times 10^{-6} \mathrm{~s}^{-1}$. Thick gray lines indicate potential temperature, with a contour interval of $10 \mathrm{~K}$.

lower-level convergence occurs in the tropics, whereas the subtropics experience divergence. Interestingly, the mountain strengthens divergence upstream but dramatically turns divergence into convergence downstream (see the convergence-divergence pattern along the mountain contours in Fig. 10b). The mechanically driven downstream convergence in the subtropics is significantly stronger than the thermally driven convergence near the equator. In a moist atmosphere, this downstream convergence is often accompanied by poleward MSE flux (Fig. 4b), which brings warm and moist air from the equator. Because the moist air from the equator may condense before reaching the downstream of the mountain, the area of the downstream convergence is likely to shift somewhat equatorward in a moist atmosphere. 
(a) Eddy relative vorticity $(0.9<$ sigma $<1.0)$

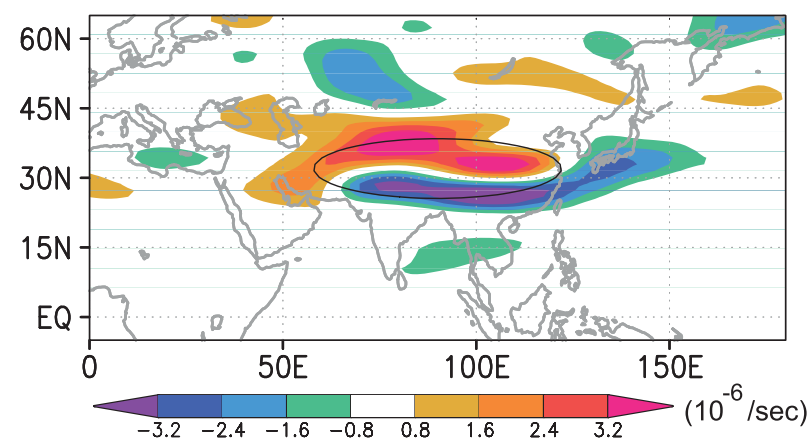

(b) Convergence $(0.9<$ sigma $<1.0)$

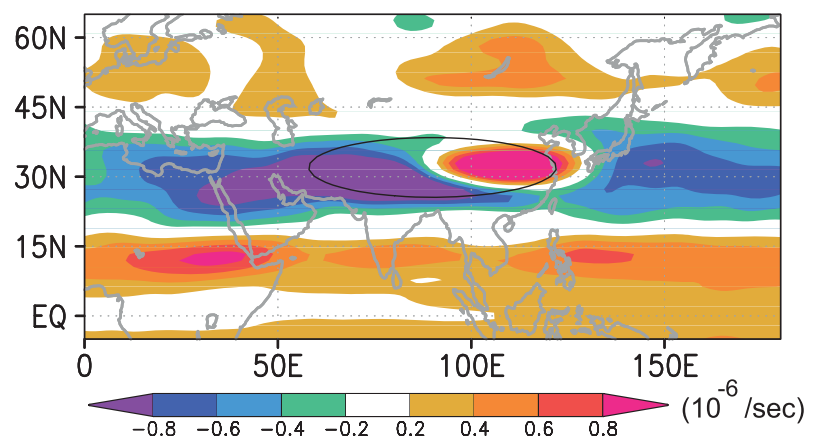

FIG. 10. (a) Low-level eddy relative vorticity $\left(10^{-6} \mathrm{~s}^{-1}\right)$ and (b) lower-level convergence $\left(10^{-6} \mathrm{~s}^{-1}\right)$ averaged from surface to the 0.9 -sigma level simulated by an idealized dry model. Mountains higher than $800 \mathrm{~m}$ are contoured.

In the experiments described here, we find that the downstream convergence can be explained by the convergence of zonal winds $(-d u / d x)$ as well as the convergence of the meridional winds $(-d v / d y)$. More quantitatively, the zonal wind convergence explains about $50 \%-80 \%$ of the upstream divergence and downstream convergence, with the meridional wind convergence explaining the remaining $20 \%-50 \%$. It is interesting to note that the convergence of meridional wind is nonnegligible, despite the narrow latitudinal extent of the imposed mountains.

Figure $9 \mathrm{~b}$ shows eddy zonal winds (shadings) and divergence (solid and dotted contours) over the mountain with isentropes (solid gray lines). Westerly winds maximize over the mountain top, approximately $3-4 \mathrm{~m} \mathrm{~s}^{-1}$ faster than other areas, which implies that zonal winds accelerate upslope of the mountains, causing divergence there. On the other hand, zonal wind speed decreases downstream, leading to downstream convergence. As expected, isentropes (thick gray lines) intersect the mountain, which makes the direct application of linear theories inadequate.

The mismatch between the convergence and vorticity field (Fig. 10) suggests that the downstream convergence may not be directly explained by potential vorticity conservation. In terms of mass conservation, forced vertical motion near the surface of topography can be simplified as $w=U(d h / d x)$ (Held et al. 2002; Smith 1980). The forced near-surface (anomalous) vertical motions decrease with height in our dry model. The decrease of $w$ with height leads to vertical stretching $(\partial w / \partial z>0)$ over downslope $(d h / d x<0)$, which in turn leads to horizontal convergence $[-(\partial u / \partial x+\partial v / \partial y)>0]$ because of mass continuity. This might indicate that the upstream divergence and downstream convergence are regional responses of zonal momentum balance to the forced vertical motions. Because Coriolis acceleration is small in the subtropics relative to midlatitudes, ageostrophic terms, such as zonal advection $[U(d U / d x)]$ is likely to be affected by the forced vertical motions.

In a moist atmosphere, we suggest that the strong downstream convergence may produce moisture convergence, provided that there is enough moisture in the subcloud layer. Moisture convergence on the downslope of the mountain can trigger strong diabatic heating in the moist atmosphere, which would strengthen crossisentropic motions. In the presence of moisture, the relative importance of the dynamical convergence is likely to decrease, with downstream moist convection and windinduced surface evaporation feedback possibly sustaining the downstream convergence (Emanuel et al. 1994). In the real atmosphere, there are many factors affecting the diabatic heating field; as such, we can only suggest, but not confirm, that this mechanically driven downstream convergence simulated by a dry model leads to a strong diabatic heating in the real atmosphere. Further research will be needed to fill the gap between this idealized model and the full AGCM.

\section{Summary and discussion}

Using numerical experiments with the GFDL AM2.1, we demonstrated that the presence of the Tibetan Plateau triggers an earlier onset of monsoon rainfall downstream, particularly over the Bay of Bengal and South China. The impact of the Tibetan Plateau on the monsoonal circulation strength is greatest in May and then rapidly decreases as the monsoon progresses into its mature phase. In July and August, during the mature phase of the monsoon, the monsoon strength is largely unaffected by the presence of the Tibetan Plateau.

In this study, we suggest that the early monsoon onset downstream of the Tibetan Plateau is mechanically driven. Westerly wind speed over the Southern Tibetan Plateau is significant in early June, making it possible for the Tibetan Plateau to affect the zonal momentum balance and near-surface convergence pattern. Over 
the Bay of Bengal, located near the southeastern Tibetan Plateau, the mechanically forced convergence will be able to support substantial moisture convergence and diabatic heating, which itself can reinforce the convergence.

Idealized experiments with a narrow Tibet indicate consistent downstream preference of rainfall in AMJ when westerly winds are significant. Unlike the fullTibet case, the downstream rainfall is not accompanied by the basinwide strengthening of monsoonal winds probably because the area of downstream convergence is located far east, which is outside the equatorial Rossby radius of deformation. Alternatively, this effect might result from the area of downstream convergence is being far from the sea. If the thermal insulator effect played a dominant role, the rainfall should move equatorward of the mountain, but this is not seen in our simulation.

We explore mechanisms of how an east-west-oriented narrow mountains in the subtropics leads to downstream convergence. Because the forced vertical motion $[w=$ $U(d h / d x)]$ works for any types of mountains with an east-west slope, it follows that east-west-oriented narrow mountains efficiently affect the zonal momentum balance in the presence of westerly winds. Future work will investigate further in detail how the forced vertical motion interacts with the zonal momentum balance to cause downstream convergence.

In the real atmosphere, where moisture-circulation feedbacks are active, the mechanically driven convergence will support moist convection provided the lower-level moisture is high enough. In the South Asian monsoon, the Bay of Bengal happens to be located near the mechanically induced convergence by the Tibetan Plateau, making it possible for the local convergence to progress into a larger-scale tropical monsoon onset with the aid of windinduced surface heat flux exchange feedback (Boos and Emanuel 2009; Boos 2008).

It is interesting to note how the low-level monsoonal winds get stronger during AMJ because of extratropical westerlies over the Tibetan Plateau. The regional monsoon onset, particularly in the Bay of Bengal and South China areas, occurs a few weeks earlier in the presence of the Tibetan Plateau. However, the earlier downstream monsoon onset is accompanied by anomalous subsidence upstream of the Tibetan Plateau in the presence of significant westerly winds, which limits the development of large-scale, zonal-mean meridional overturning circulation (MMC) strength covering both upstream and downstream of the Tibetan Plateau. Similarly, the timing of the eddy-mediated regime transition (Bordoni and Schneider 2008) defined by the zonal-mean MMC does not appear to be strongly altered by the Tibetan Plateau.
Acknowledgments. HSP thanks In-Sik Kang and Benjamin Lintner for helpful comments. Conversation with Tapio Schneider was particularly helpful. The simulations were carried out on Caltech's Geological and Planetary Sciences Dell cluster. This work was partly funded by NSF Grant EAR-0909195.

\section{REFERENCES}

Abe, M., A. Kitoh, and T. Yasunari, 2003: An evolution of the Asian summer monsoon associated with mountain upliftSimulation with the MRI atmosphere-ocean coupled GCM. J. Meteor. Soc. Japan, 81, 909-933.

Annamalai, H., K. Hamilton, and K. R. Sperber, 2007: South Asian summer monsoon and its relationship with ENSO in the IPCC AR4 simulations. J. Climate, 20, 1071-1092.

Boos, W. R., 2008: Wind-evaporation feedback, angular momentum conservation, and abrupt onset of monsoons. Ph.D dissertation, MIT, $174 \mathrm{pp}$.

_- and K. A. Emanuel, 2009: Annual intensification of the Somali jet in a quasi-equilibrium framework: Observational composites. Quart. J. Roy. Meteor. Soc., 135, 319-335.

— monsoon by orographic insulation versus plateau heating. Nature, 463, 218-222.

Bordoni, S., and T. Schneider, 2008: Monsoons as eddy-mediated regime transitions of the tropical overturning circulation. Nat. Geosci., 1, 515-519, doi:10.1038/ngeo248.

Charney, J. G., 1975: Dynamics of deserts and drought in Sahel. Quart. J. Roy. Meteor. Soc., 101, 193-202.

Chou, C., J. D. Neelin, and H. Su, 2001: Ocean-atmosphere-land feedbacks in an idealized monsoon. Quart. J. Roy. Meteor. Soc., 127, 1869-1891.

Cook, K. H., and I. M. Held, 1992: The stationary response to largescale orography in a general circulation model and a linear model. J. Atmos. Sci., 49, 525-539.

Emanuel, K. A., 1987: An air-sea interaction model of intraseasonal oscillations in the tropics. J. Atmos. Sci., 52, 1529-1534.

— J. D. Neelin, and C. S. Bretherton, 1994: On large-scale circulations in convecting atmosphere. Quart. J. Roy. Meteor. Soc., 120, 1111-1143.

Flohn, H., 1957: Large-scale aspects of the "summer monsoon" in South and East Asia. J. Meteor. Soc. Japan, 35, 180-186.

Frierson, D. M. W., and N. A. Davis, 2011: The seasonal cycle of midlatitude static stability over land and ocean in global reanalyses. Geophys. Res. Lett., 38, L13803, doi:10.1029/ 2011 GL047747.

Gadgil, S., 2003: The Indian monsoon and its variability. Annu. Rev. Earth Planet. Sci., 31, 429-467.

GFDL Global Atmospheric Model Development Team, 2004: The new GFDL global atmosphere and land model AM2-LM2: Evaluation with prescribed SST simulations. J. Climate, 17, 4641-4673.

Gill, A. E., 1980: Some simple solutions for heat-induced tropical circulation. Quart. J. Roy. Meteor. Soc., 106, 447-462.

Hahn, D. G., and S. Manabe, 1975: The role of mountains in the South Asian monsoon circulation. J. Atmos. Sci., 32, 1515-1541.

Held, I. M., and M. J. Suarez, 1994: A proposal for the intercomparison of the dynamical cores of atmospheric general circulation models. Bull. Amer. Meteor. Soc., 73, 1825-1830.

_ - M.-F. Ting, and H.-I. Wang, 2002: Northern winter stationary waves: Theory and modeling. J. Climate, 15, 2125-2144. 
Hsu, H. H., C. T. Terng, and C. T. Chen, 1999: Evolution of largescale circulation and heating during the first transition of Asian summer monsoon. J. Climate, 12, 793-810.

Kang, I.-S., and I. M. Held, 1986: Linear and nonlinear diagnostic models of stationary eddies in the upper troposphere during northern summer. J. Atmos. Sci., 43, 3045-3057.

Kiehl, J. T., J. J. Hack, G. B. Bonan, B. A. Boville, D. L. Williamson, and P. J. Rasch, 1998: The National Center for Atmospheric Research Community Climate Model: CCM3. J. Climate, 11, 1131-1149.

Kutzbach, J. E., P. J. Guetter, W. F. Ruddiman, and W. L. Prell, 1989: The sensitivity of climate to Late Cenozoic uplift in southern Asia and the American west: Numerical experiments. J. Geophys. Res., 103, 14 451-14 510.

Lin, S.-J., 2004: A "vertically Lagrangian" finite-volume dynamical core for global models. Mon. Wea. Rev., 132, 2293-2307.

Luo, H., and M. Yanai, 1984: The large-scale circulation and heat source over the Tibetan Plateau and surrounding areas during the early summer of 1979. Part II: Heat and moisture budgets. Mon. Wea. Rev., 112, 966-989.

Molnar, P., W. R. Boos, and D. S. Battisti, 2010: Orographic controls on climate and paleoclimate of Asia: Thermal and mechanical roles for the Tibetan Plateau. Annu. Rev. Earth Planet. Sci., 38, 77-102.

Navarra, A., W. F. Stern, and K. Miyakoda, 1994: Reduction of the Gibbs oscillation in spectral model simulations. J. Climate, 7, 1169-1183.

Neelin, J. D., I. M. Held, and K. H. Cook, 1987: Evaporation-wind feedback and low-frequency variability in the tropical atmosphere. J. Atmos. Sci., 44, 2341-2348.

Prell, W. L., and J. E. Kutzbach, 1992: Sensitivity of the Indian monsoon to forcing parameters and implications for its evolution. Nature, 360, 647-652.

Prive, N. C., and R. A. Plumb, 2007: Monsoon dynamics with interactive forcing. Part II: Impact of eddies and asymmetric geometries. J. Atmos. Sci., 64, 1431-1442.

Rodwell, M. J., and B. J. Hoskins, 2001: Subtropical anticyclones and summer monsoons. J. Climate, 14, 3192-3211.
Sato, T., and F. Kimura, 2007: How does the Tibetan Plateau affect the transition of Indian monsoon rainfall? Mon. Wea. Rev., 135, 2006-2015.

Smith, R. B., 1980: Linear theory of stratified hydrostatic flow past an isolated mountain. Tellus, 32A, 348-364.

Smith, T. M., R. W. Reynolds, R. E. Livezey, and D. C. Stokes, 1996: Reconstruction of historical sea surface temperatures using empirical orthogonal functions. J. Climate, 9, 1403-1420.

Takahashi, K., and D. S. Battisti, 2007b: Processes controlling the mean tropical Pacific precipitation pattern. Part II: The SPCZ and the South Pacific dry zone. J. Climate, 20, 5696-5706.

Uppala, S. M., and Coauthors, 2005: The ERA-40 Re-Analysis. Quart. J. Roy. Meteor. Soc., 131, 2961-3012.

Webster, P. J., and Coauthors, 1998: Monsoons-Processes, predictability, and the prospects for prediction. J. Geophys. Res., 103, 14 451-14 510.

Wu, G.-X., and Y.-S. Zhang, 1998: Tibetan Plateau forcing and the timing of the monsoon onset over South Asia and the South China Sea. Mon. Wea. Rev., 126, 913-927.

— and Coauthors, 2007: The influence of mechanical and thermal forcing by the Tibetan Plateau on Asian climate. J. Hydrometeor., 8, 770-789.

Xie, P., and P. A. Arkin, 1997: Global precipitation: A 17-year monthly analysis based on gauge observations, satellite estimates, and numerical model outputs. Bull. Amer. Meteor. Soc., 78, 2539-2558.

Yanai, M., and G. X. Wu, 2006: Effects of the Tibetan Plateau. The Asian Monsoon, B. Wang, Ed., Springer, 513-549.

Yasunari, T., K. Saito, and K. Takata, 2006: Relative role of largescale orography and land surface processes in the global hydroclimate. Part I: Impacts on monsoon systems and the tropics. J. Hydrometeor., 7, 626-641.

Yeh, T. C., S. W. Luo, and P. C. Chu, 1957: The wind structure and heat balance in the lower troposphere over Tibetan Plateau and its surrounding. Acta Meteor. Sin., 28, 108-121.

Yin, M. T., 1949: A synoptic-aerologic study of the onset of the summer monsoon over India and Burma. J. Meteor., 6, 394 400 . 